and indicates the road. What if a frail, old patient presents with a dilated and dissected root with a tear into an already aneurysmatic arch? The tailor watches the surgeon who takes his or her time and goes out in a more difficult situation of a root and arch replacement.
See Article page 1698.

\section{Commentary: The human factor in repair of acute dissection}

\author{
Amedeo Anselmi, MD, PhD \\ "A perfection of means, and confusion of aims, seems \\ to be our main problem."
}

\section{—Albert Einstein}

Advances in our discipline have occurred at an increasing pace during the past decade: technologies enabling reliable transcatheter and hybrid valve therapies, numbers of novel devices (mainly for transcatheter/hybrid applications) being conceived, improvement/standardization of existing surgical techniques/prostheses, diffusion of minimally invasive approaches, artificial intelligence, computer-assisted surgery, and so on. Many innovations shall not attain the stage of routine clinical application, yet major investments continue to be poured into the most promising fields. Surgery of the thoracic aorta has participated in this evolution; for example, with different branched or hybrid prostheses adapting to variable anatomies for extensive aortic replacement in 1 operation, refined brain and organ protection (selective antegrade cerebral perfusion representing a powerful and nearly unmissable tool), multiple options for

\footnotetext{
From the Division of Thoracic and Cardiovascular Surgery, Pontchaillou University Hospital, Rennes, France.

Disclosures: The author reported no conflicts of interest.

The Journal policy requires editors and reviewers to disclose conflicts of interest and to decline handling or reviewing manuscripts for which they may have a conflict of interest. The editors and reviewers of this article have no conflicts of interest.

Received for publication Jan 17, 2021; revisions received Jan 17, 2021; accepted for publication Jan 20, 2021; available ahead of print Jan 28, 2021.

Address for reprints: Amedeo Anselmi, MD, PhD, Division of Thoracic and Cardiovascular Surgery, Pontchaillou University Hospital, 2 Rue Henri le Guilloux, Rennes, France (E-mail: amedeo.anselmi@chu-rennes.fr).

J Thorac Cardiovasc Surg 2022;164:1709-10

$0022-5223 / \$ 36.00$

Copyright (C) 2021 by The American Association for Thoracic Surgery

https://doi.org/10.1016/j.jtcvs.2021.01.071
}

\section{Reference}

1. Lau C, Robinson B, Farrington WJ, Rahouma M, Gambardella I, Gaudino M, et al A tailored strategy for repair of acute type A aortic dissection. J Thorac Cardiovasc Surg. 2022;164:1698-707.e3.

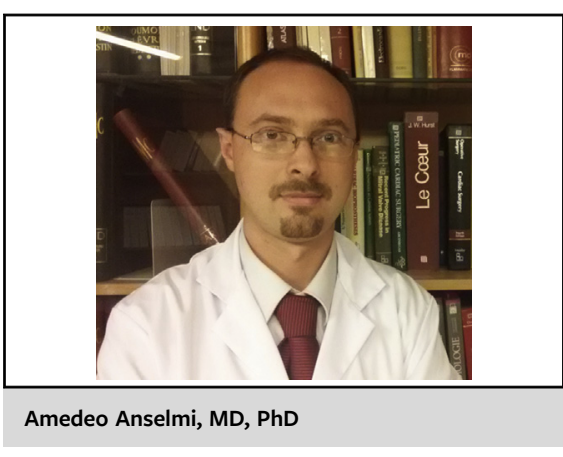

CENTRAL MESSAGE

Reasonable clinical judgment is the compass for operative management of type A dissection. Nonetheless, this proficiency requires substantial experience and its transmission is not easily obtained.

root management, and endovascular and hybrid repair. This has occurred to the great benefit of many patients.

In this context, decision making about the most adapted management strategy in individual patients, and the relative role of alternative techniques, represents the main feature and challenge of current cardiac surgery practice, to the point of redefining the role of cardiac surgeons within Heart Teams. The current, remarkable article from Lau and colleagues at Weill Cornell University ${ }^{1}$ reminds us that our philosophical approach should be patient-oriented rather than disease-oriented, and that the goal of surgery for acute type A dissection is to save a patient's life in an emergency setting. The risks of the operation should undoubtedly be balanced against the patient's life expectancy and overall profile. The performance of an extensive repair at primary surgery (at the aortic root and/or arch) represents a marker of greater aggressiveness of the disease. As such, it is associated with an increased need for reintervention at followup. Conservative repair patients were older in the current 
series, but they had a significantly lower rate of reintervention at follow-up than the extensive repair group. Unfortunately, it remains unclear whether this can be attributed to censoring with death due to nonaortic causes, to abstention from reintervention due to age/comorbidities/fragility, or to other factors.

The current series also underlines the importance of surgical experience for appropriate decision making. The border between favorable and unfavorable risk-to-benefit ratio of different surgical options may be difficult to appreciate during repair of acute type A dissection. Any operating surgeon dealing with this protean disease has had the experience of dynamically changing the operative plan when examining the root or the open arch under the constraint of limited circulatory arrest time: Often the site/extent of the entry tear and the status of the epiaortic vessels become visible only at that stage. The authors did not refrain from performing more complex operations when they believed this was in the interest of patients. Anatomical findings might demand opposite strategies than suggested by the patient's profile, and gray zone situations are common in type A dissection. Here resides the great pedagogical challenge we are facing: Teaching the surgical feeling for decision making in a rapidly evolving discipline with growing technological/technical content and a relatively low number of cases. In fact, the effectiveness of conservative approaches for most patients does not exempt operating surgeons from mastering the largest possible arsenal of solutions. We appreciate these results from an expert aortic center: Standardizing and perpetuating excellence to younger generations of surgeons may be now more challenging than ever.

\section{Reference}

1. Lau C, Robinson NB, Farrington WJ, Rahouma M, Gambardella I, Gaudino M, et al. A tailored strategy for repair of acute type A aortic dissection. J Thorac Cardiovasc Surg. 2022;164:1698-707.e3.
See Article page 1698

\section{Commentary: A tailored strategy for repair of acute type $A$ aortic dissection: Balancing risk versus benefit}

\author{
Wael Ahmad, MD, ${ }^{\mathrm{a}}$ and Oliver J. Liakopoulos, $\mathrm{MD}^{\mathrm{b}}$
}

Current surgical aortic repair strategies for the treatment of acute type A aortic dissection vary in extent and technical complexity. Consequently, clinical outcomes, including

\footnotetext{
From the ${ }^{\mathrm{a} D e p a r t m e n t}$ of Vascular and Endovascular Surgery, University Hospital of Cologne, Cologne, Germany; and ${ }^{b}$ Department of Cardiac Surgery, KerckhoffClinic Bad Nauheim, Campus Kerckhoff, University of Giessen, Giessen, Germany.

Disclosures: The authors reported no conflicts of interest.

The Journal policy requires editors and reviewers to disclose conflicts of interest and to decline handling or reviewing manuscripts for which they may have a conflict of interest. The editors and reviewers of this article have no conflicts of interest.

Received for publication Jan 10, 2021; revisions received Jan 10, 2021; accepted for publication Jan 11, 2021; available ahead of print Jan 20, 2021.

Address for reprints: Oliver J. Liakopoulos, MD, Department of Cardiac Surgery, Kerckhoff-Clinic Bad Nauheim, Campus Kerckhoff, University of Giessen, Benekestr. 2-8, 61231 Bad Nauheim, Germany (E-mail: o.liakopoulos@ kerckhoff-klinik.de).

J Thorac Cardiovasc Surg 2022;164:1710-1

$0022-5223 / \$ 36.00$

Copyright (c) 2021 by The American Association for Thoracic Surgery

https://doi.org/10.1016/j.jtcvs.2021.01.038
}

Check for updates

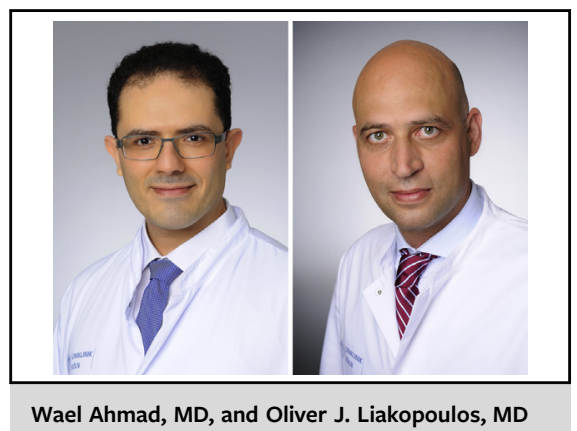

CENTRAL MESSAGE

This study underscores the safety and efficacy of a wellbalanced, patient-risk-orientated operative strategy in patients with acute type A aortic dissection.

operative mortality, complication rates, and reintervention rates, differ depending on the chosen repair strategy, extent of repair, and the underlying aortic pathology. The expert consensus document of the European Association for Cardio-Thoracic Surgery and the European Society for Vascular Surgery recommends performing extended 